06

\title{
Исследование скоростных зависимостей напряжения пластического течения и разрушения стали 09Г2СА-А при нормальной и повышенной температурах
}

\author{
(C) Г.И. Канель, ${ }^{1}$ Г.В. Гаркушин, ${ }^{1,2}$ А.С. Савиных, ${ }^{1,2}$ С.В. Разоренов, ${ }^{1,2}$ С.А. Атрошенко \\ 1 1Объединенный институт высоких температур РАН, \\ 125412 Москва, Россия \\ ${ }^{2}$ Институт проблем химической ффизики РАН, \\ 142432 Черноголовка, Московская обл., Россия \\ ${ }^{3}$ Институт проблем машиноведения РАН, \\ 199178 Санкт-Петербург, Россия \\ e-mail: garkushin@ficp.ac.ru
}

Поступило в Редакцию 22 апреля 2021 г.

В окончательной редакции 22 апреля 2021 г.

Принято к публикации 20 июня 2021 г.

Проведены измерения динамического предела упругости и откольной прочности реакторной стали 09Г2СА-А при ударном сжатии путем регистрации и последующего анализа полных волновых профилей. Определены температурно-скоростные зависимости сопротивления высокоскоростному деформированию и разрушению стали при нормальной и повышенной температурах. Результаты измерений прочностных характеристик стали при отколе дополнены металлографическим анализом зоны разрушения и сопоставлены с данными для реакторной стали 15Х2НМФА и железа Армко.

Ключевые слова: ферритно-перлитная сталь, ударные волны, деформация, температура, динамический предел упругости, откольная прочность.

DOI: 10.21883/JTF.2021.11.51531.116-21

\section{Введение}

Для хранения и перевозки к месту переработки отработанного ядерного топлива в настоящее время используются металлобетонные контейнеры, металлические элементы которых состоят из листового проката, кольцевых поковок (комингс), поковок типа плит и других элементов из низколегированной кремнемарганцевой стали марки 09Г2СА-А [1]. Эта сталь широко применяется также для различных деталей и элементов металлоконструкций, работающих при температуре от -70 до $+425^{\circ} \mathrm{C}$ под давлением. Исследование динамических прочностных характеристик феррито-перлитной стали марки 09Г2СА-А стимулируется необходимостью прогнозирования последствий интенсивных ударных воздействий природного, техногенного или террористического характера на конструкции ядерной энергетики [2]. Математические модели и определяющие соотношения, используемые при расчетном прогнозировании действия удара, взрыва и других интенсивных импульсных воздействий, строятся на основе экспериментальных данных о прочностном поведении конструкционных материалов при скоростях деформирования в диапазоне $10^{3}-10^{6} \mathrm{~s}^{-1}$. Имеются также вопросы академического характера относительно влияния температуры и скорости деформирования на сопротивление пластическому деформированию и разрушению сталей и сплавов. Первый из них связан с соотношением динамической прочности материала с его динамическим пределом текучести. Хотя во многих случаях материалы с более высокой откольной прочностью (прочностью на растяжение, реализуемой в условиях ударно-волнового нагружения) обладают и более высокими значениями динамического предела упругости, эта корреляция не универсальна. Второй важный вопрос связан с влиянием температуры на сопротивление высокоскоростному деформированию и разрушению. В связи с имеющейся неопределенностью представляет интерес накопления экспериментальных данных и их сопоставление для сталей и сплавов с разными прочностными свойствами [3-5].

В настоящей работе представлены результаты исследований динамической прочности низколегированной ферритно-перлитной стали 09Г2СА-А при нормальной и повышенной температурах в субмикросекундном диапазоне длительности ударной нагрузки.

\section{1. Исследуемый материал}

Проведены исследования с низколегированной ферритно-перлитной сталью марки 09Г2СА-А, химический состав которой приведен в табл. 1. Образцы толщиной от 0.17 до $4 \mathrm{~mm}$ были вырезаны из листовой кованой обечайки электроэрозионным способом. Кованная обечайка была предварительно подвергнута термообработке, которая заключалась в закалке от $930^{\circ} \mathrm{C}$ в воду с 
Таблица 1. Химический состав стали 09Г2СА-А

\begin{tabular}{c|c|c|c|c|c|c|c|c|c|c|c|c}
\hline \multicolumn{10}{c}{ Содержание элементов, \% } \\
\hline $\mathrm{C}$ & $\mathrm{Si}$ & $\mathrm{Mn}$ & $\mathrm{P}$ & $\mathrm{S}$ & $\mathrm{Cr}$ & $\mathrm{Ni}$ & $\mathrm{V}$ & $\mathrm{Ti}$ & $\mathrm{Al}$ & $\mathrm{Nb}$ & $\mathrm{N}$ & $\mathrm{As}$ \\
\hline 0.08 & 0.6 & 1.56 & 0.008 & 0.003 & 0.1 & 0.23 & 0.04 & 0.004 & 0.032 & 0.05 & 0.01 & 0.008
\end{tabular}

последующим отпуском при $660-670^{\circ} \mathrm{C}$ и охлаждением в воздухе. Сталь 09Г2СА-А после термообработки имела феррито-перлитную структуру с мелкозернистой структурой, размер зерна составил $15-30 \mu \mathrm{m}$. По справочным данным предел текучести стали $\sigma_{0.2}$ при комнатной температуре после закалки и отпуска составляет $315-365 \mathrm{MPa}$, предел прочности 450-490 МРа. С увеличением температуры до $500^{\circ} \mathrm{C}$ предел текучести падает до $180 \mathrm{MPa}$, а предел прочности - до $360 \mathrm{MPa}$.

Поскольку сталь низколегированная, при обработке экспериментальных данных для комнатной температуры использовалась ударная адиабата $\alpha$-железа с плотностью $\rho_{0}=7.85 \mathrm{~g} / \mathrm{cm}^{3}$ и продольной скоростью звука $c_{l}=5.9 \mathrm{~km} / \mathrm{s}$ в виде $U_{S}=4.63+1.33 u_{p}$, где $U_{S}-$ скорость ударной волны, $u_{p}-$ массовая скорость, построенная по приведенным в [6] экспериментальным данным, a для $600^{\circ} \mathrm{C}$ с учетом температурных зависимостей скоростей звука $[7,8]-$ в виде $U_{S}=4.37+1.33 u_{p}$; плотность и продольная скорость звука в этих условиях составляли $7.66 \mathrm{~g} / \mathrm{cm}^{3}$ и $5.5 \mathrm{~km} / \mathrm{s}$ соответственно.

\section{2. Постановка экспериментов}

Эксперименты проведены на стенде, включающем газовую пушку калибром $50 \mathrm{~mm}$ для генерации импульсов ударного сжатия в исследуемых образцах и лазерный допплеровский интерферометрический измеритель скорости VISAR [9] с временным разрешением $\sim 1 \mathrm{~ns}$ для регистрации эволюции формируемых ударом волн сжатия. Схема экспериментов показана на рис. 1. Плоские ударники из меди или вольфрама толщиной от 0.04 до $2 \mathrm{~mm}$ наклеивались на подложку из полиметилметакрилата (РММА) толщиной $5 \mathrm{~mm}$, расположенную на торце пустотелого дюралюминиевого (Д16Т) снаряда. Использование подложки позволяет избегать прогиба тонких ударников в процессе ускорения последнего в стволе пушки. Скорость метания варьировалась подбором давления рабочего газа (воздух или гелий) и составляла в этих экспериментах $340 \pm 10 \mathrm{~m} / \mathrm{s}$ или $590 \pm 20 \mathrm{~m} / \mathrm{s}$. Измерения проведены при комнатной и повышенной до $600-610^{\circ} \mathrm{C}$ температурах образцов. В последнем случае использовались резистивные нагреватели, расположенные на расстоянии $2-2.5 \mathrm{~mm}$ от тыльной поверхности образца. Температура контролировалась двумя термопарами хромель-алюмель с точностью $\pm 3^{\circ} \mathrm{C}$. Время нагрева образцов, как правило, составляло $600 \pm 30 \mathrm{~s}$. Измерения скорости удара проводились с применением электроконтактных датчиков (Pin) только в опытах

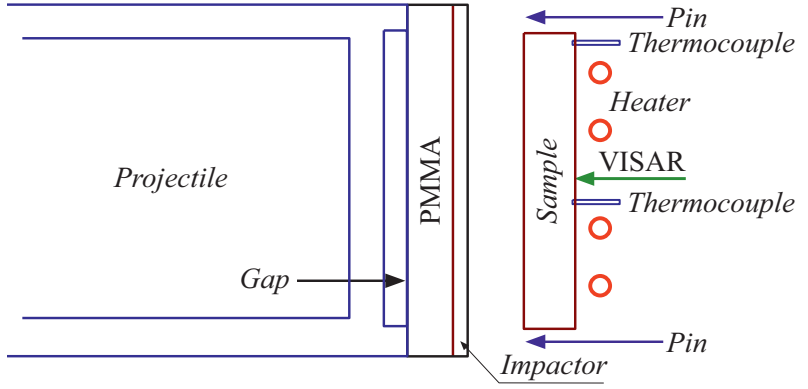

Рис. 1. Схема экспериментальной сборки.

без нагрева образцов. Все эксперименты проведены в вакууме.

Помимо ударно-волновых экспериментов с регистрацией волновых профилей в работе проведены металлографические исследования зоны откольного разрушения сохраненных после ударного сжатия образцов на поперечных шлифах с помощью оптического микроскопа Axio Observer Z1M в светлом поле и в контрасте C-DIC после травления в нитале (4\%-й раствор $\mathrm{HNO}_{3}$ в спирте).

\section{3. Результаты измерений}

На рис. 2 показаны результаты опытов с образцами стали 09Г2СА-А номинальной толщины 4 и $2 \mathrm{~mm}$, а на рис. 3 - фотографии диаметральных сечений образцов в области откола. Эксперименты при комнатной температуре проведены с двумя соотношениями толщин ударника и образца $-1 / 2$ и 1/4. В западных, в первую очередь американских, работах, как правило, используются ударники с толщиной, равной половине толщины образца. Это соотношение толщин приводит, как будет обсуждаться ниже, к дополнительной погрешности при определении величины откольной прочности.

На профилях скорости свободной поверхности фиксируется последовательно выход на поверхность упругого предвестника (упругой волны сжатия, первая „ступенька“), пластической ударной волны, следующей за ней области постоянства параметров („плато“) и затем части волны разрежения. Длительность плато определяется временем реверберации волн в ударнике и соответственно она тем больше, чем больше толщина ударника. Скорость распространения упругого предвестника практически равна продольной скорости звука $c_{l}=\sqrt{(K+4 G / 3) / \rho}$, а скорость пластической ударной 

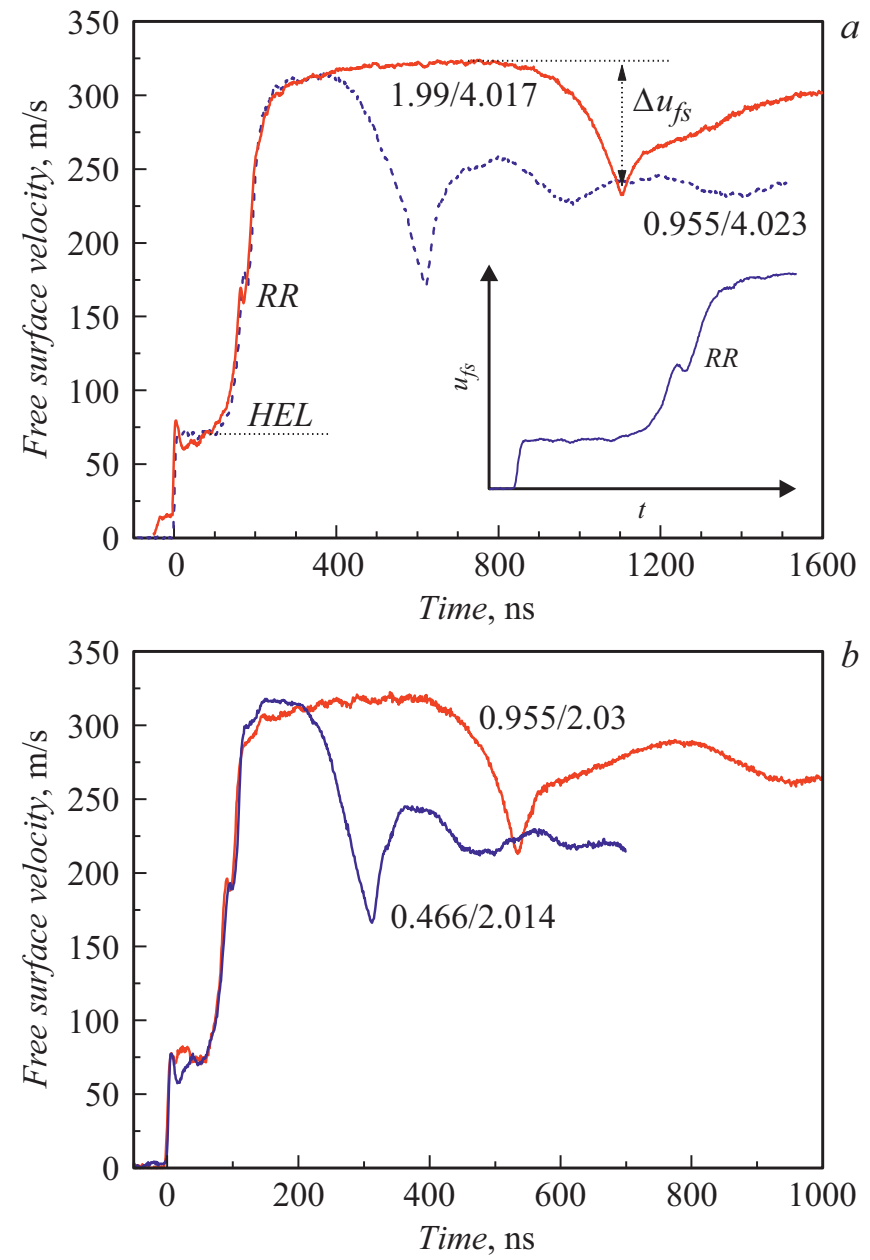

Рис. 2. Профили скорости свободной поверхности образцов стали 09Г2СА-А с номинальной толщиной $4(a)$ и $2 \mathrm{~mm}(b)$. Числами у профилей показаны фактические значения толщины медного ударника и образца. На вставке рисунка $(a)$ показана фронтальная часть волнового профиля, на которой четко проявляется переотражение RR упругой волны от пластической ударной волны. HEL (Hugoniot Elastic Limit) — динамический предел упругости.

волны определяется объемной сжимаемостью материала и соответственно близка к объемной скорости звука $c_{b}=\sqrt{K / \rho}[10,11]$ при умеренных амплитудах ударного сжатия.

Амплитуда упругого предвестника определяется динамическим пределом упругости материала HEL (Hugoniot elastic limit) и равна

$$
\sigma_{\mathrm{HEL}}=0.5 u_{\mathrm{HEL}} \rho_{0} c_{l}
$$

где $u_{\mathrm{HEL}}-$ скачек скорости свободной поверхности в предвестнике. Предел упругости при одномерной деформации связан с пределом текучести в обычном понимании $\sigma_{T}$ соотношением

$$
\sigma_{T}=\frac{3}{2} \sigma_{\mathrm{HEL}}\left(1-c_{b}^{2} / c_{l}^{2}\right) .
$$

После отражения импульса сжатия от свободной поверхности внутри образца генерируются растягивающие напряжения, в результате чего инициируется его разрушение - откол. При этом происходит релаксация растягивающих напряжений и формируется волна сжатия (откольный импульс), выход которой на поверхность образца обычно вызывает второй подъем ее скорости или останавливает ее падение в разгрузочной части падающего импульса сжатия. Декремент скорости поверхности $\Delta u_{f s}$ при ее спаде от максимума до значения перед фронтом откольного импульса пропорционален величине разрушающего напряжения - откольной прочности материала в данных условиях нагружения. В линейном (акустическом) приближении величина откольной прочности $\sigma_{s p}$ материала определяется как [10]:

$$
\sigma_{s p}=\frac{1}{2} \rho_{0} c_{b}\left(\Delta u_{f s}+\delta\right),
$$

где $\delta$ - поправка на искажение профиля скорости вследствие различия скоростей упругого фронта откольного импульса и скорости пластической части падающей волны разгрузки перед ним [4]. Непосредственно из сопоставления волновых профилей на рис. 2 видно, что величина $\Delta u_{f s}$ в опытах с толстым ударником

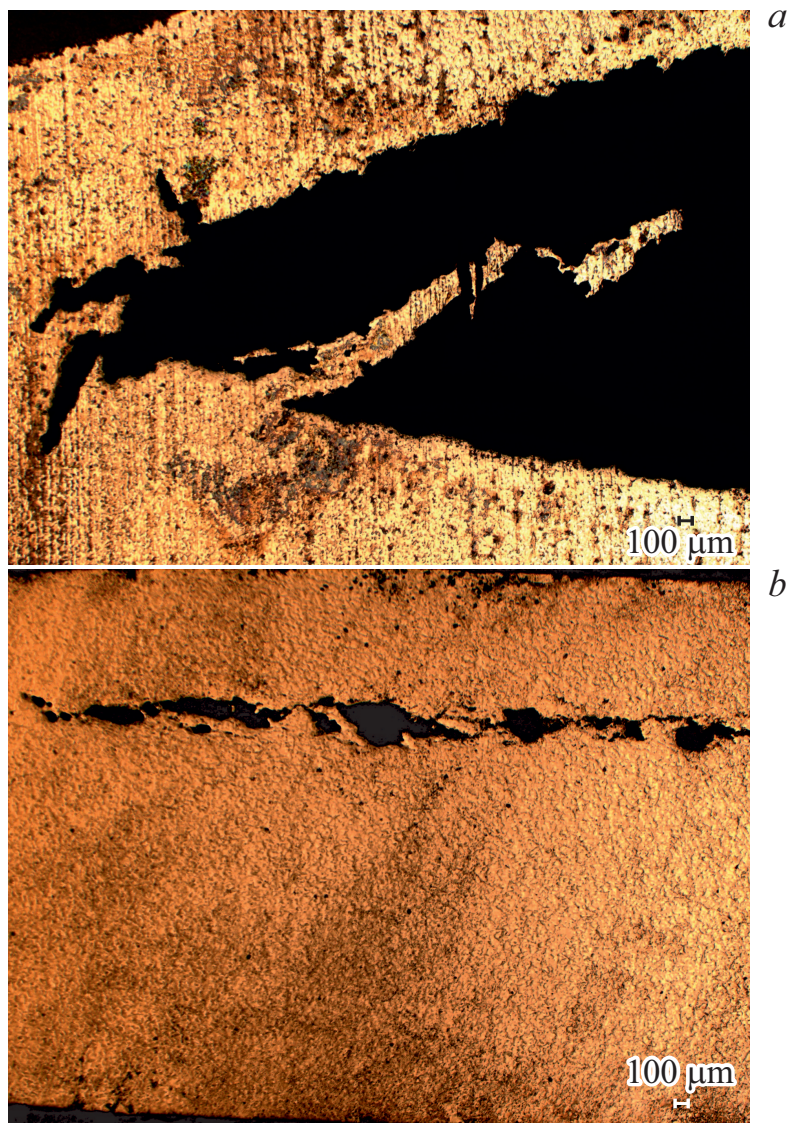

Рис. 3. Фотографии периферийных частей сечений образцов стали толщиной $4 \mathrm{~mm}$ после опытов, показанных на рис. 2: $a-$ при нагружении $2 \mathrm{~mm}$ ударником $(\times 25), b-$ при нагружении $0.96 \mathrm{~mm}$ ударником. 

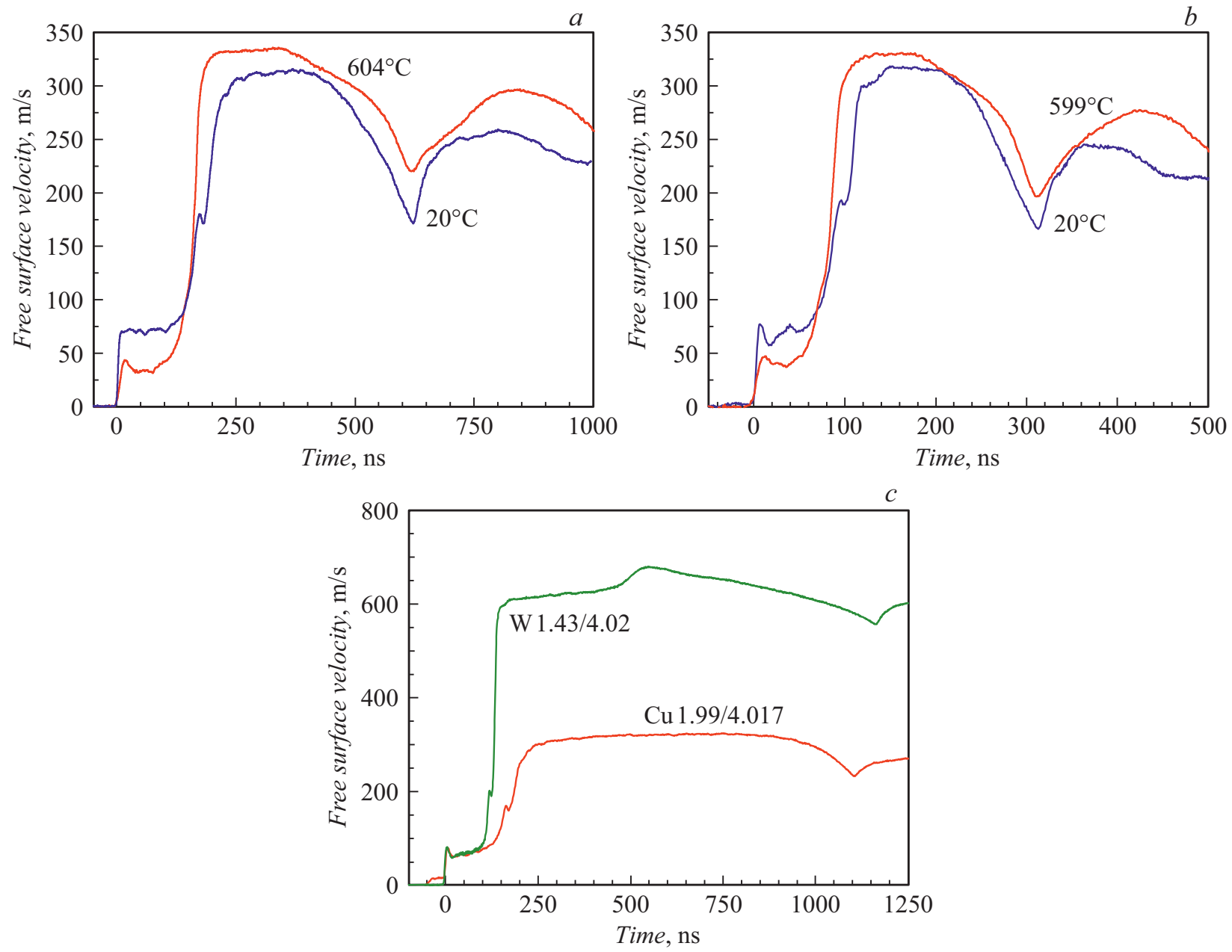

Рис. 4. Результаты опытов с образцами стали 09Г2СА-А: $a$ - профили скорости свободной поверхности образцов с номинальной толщиной $4 \mathrm{~mm}$ при нормальной и повышенной температурах, условия опытов соответствуют пунктам 1 и 14 табл. $2 ; b-$ то же для толщины $2 \mathrm{~mm}$, условия опытов соответствуют пунктам 3 и 15 табл. 2; $c$ - профили, полученные при скоростях удара $340 \pm 10 \mathrm{~m} / \mathrm{s}$ и $590 \pm 20 \mathrm{~m} / \mathrm{s}$, условия соответствуют пунктам 2 и 13 табл. 2.

значительно меньше, чем в опыте с тонким ударником. Эта разница, по крайней мере, отчасти, объясняется упомянутым искажением волнового профиля при распространении возмущений от плоскости откола к свободной тыльной поверхности. В данной постановке экспериментов откол происходит на расстоянии от свободной поверхности, примерно равном толщине ударника. В опыте с более толстым ударником зона откольного разрушения больше удалена от тыльной поверхности и соответственно на большем расстоянии накапливается большее искажение. В наших расчетах учитывалась также нелинейность сжимаемости материала $[10,12]$. Толщина откольной пластины $h_{s p}$ оценивалась по периоду колебаний скорости на волновом профиле $\Delta t$ как $h_{s p}=c_{l} \Delta t / 2$.

На представленных волновых профилях видны дополнительные ступеньки $R R$, которые появились после отражения упругого предвестника от свободной поверхности и взаимодействия образовавшейся отраженной упругой волны разгрузки с пластической ударной вол- ной [11]. Такое переотражение наблюдается не всегда, возможность его образования, а также амплитуда переотраженной волны и ее затухание связаны с релаксационными свойствами материала в состоянии перед пластической ударной волной. Эта особенность и ее детали для стали 09Г2СА-А обсуждаются в работе [13].

На фотографиях, показанных на рис. 3, видно, что в зависимости от запаса кинетической энергии в откалывающейся пластине откольное разрушение может иметь различную степень завершенности. В отличие от разрушения одной или несколькими магистральными трещинами в обычных условиях, откольное разрушение происходит путем зарождения, роста и слияния многочисленных трещин или пор с образованием развитой поверхности разрушения. Более корректно говорить о зоне разрушения конечной толщины, в пределах которой разрушение может иметь несколько локализаций и образовывать множественный откол.

На рис. 4, $a, b$ сопоставлены результаты опытов с образцами стали 09Г2СА-А номинальной толщины 4 
и $2 \mathrm{~mm}$ при повышенной температуре с результатами при комнатной температуре.

В экспериментах при скорости соударения $590 \pm 20 \mathrm{~m} / \mathrm{s}$ было зафиксировано расщепление пластической ударной волны (рис. 4,c) вследствие начала известного [14] полиморфного превращения $\alpha \rightarrow \varepsilon$ $($ ОЦК $\rightarrow$ ППУ) при сжатии. Давление начала превращения стали, определяемое по параметрам первой пластической ударной волны, составляет $12.4 \mathrm{GPa}$, что несколько ниже давления превращения железа (13 GPa), и что, вероятно, связано с присутствием марганца в составе стали. Можно отметить также увеличенную амплитуду переотраженной упругой волны $R R$ в опыте с более высоким давлением ударного сжатия. Для идеального упругопластического материала с постоянным пределом текучести амплитуда переотраженной волны не должна зависеть от конечного давления ударного сжатия [11].

\section{1. Откольная прочность стали 09Г2СА-А}

На рис. 5 суммированы результаты измерений откольной прочности стали $\sigma_{s p}$ в виде ее зависимостей от скорости расширения вещества $\dot{V} / V_{0}$ (скорости деформирования) в волне разрежения перед откольным импульсом, которая определялась как

$$
\frac{\dot{V}}{V_{0}}=\frac{\dot{u}_{f s r}}{2 c_{0}}
$$

где $\dot{u}_{f s r}$ - скорость торможения поверхности перед фронтом откольного импульса, $c_{0}$ - первый член линейной зависимости $U_{s}-u_{p}$ (ударной адиабаты), принимающий значение объемной скорости звука при нулевом

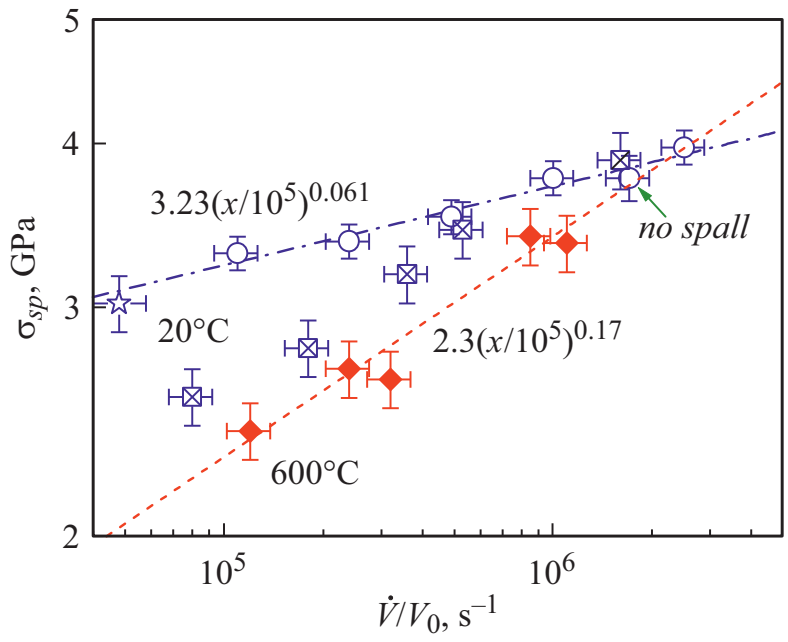

Рис. 5. Зависимость откольной прочности стали 09Г2СА-А от скорости деформирования в волне разрежения падающего импульса сжатия. Открытыми кружками показаны результаты опытов с тонкими ударниками при комнатной температуре, квадратами - результаты опытов с толстыми ударниками, ромбами - результаты высокотемпературных измерений, звездочкой показан результат эксперимента с полиморфным превращением $\alpha \rightarrow \varepsilon$. давлении. Ранее $[15,16]$ было показано, что зависимости такого вида преобразуются в зависимости скорости разрушения (скорости роста объема несплошностей) от напряжения. График на рис. 5 имеет следующие специфические особенности, отличающие поведение стали 09Г2СА-А от других металлов и сплавов. При скоростях деформации меньше $5 \cdot 10^{5} \mathrm{~s}^{-1}$ имеет место большое расхождение в величинах откольной прочности, полученных в опытах с тонкими и с толстыми ударниками. Для других материалов аналогичная обработка подобных волновых профилей с учетом их искажения в соответствии с соотношением (3) не давала большой выходящей за пределы естественной погрешности разницы в результатах. С увеличением скорости деформации, т.е. с переходом к все более тонким образцам, это расхождение постепенно исчезает. При этом уменьшается также разница в значениях откольной прочности при комнатной температуре и при $600^{\circ} \mathrm{C}$. Все опыты при повышенной температуре проведены с тонкими ударниками, поскольку такая постановка экспериментов сопряжена с наименьшими искажениями волновых профилей. Из рис. 5 видно, что результаты измерений, охватывающие более чем один порядок скоростей деформации, с приемлемой точностью аппроксимируются степенными зависимостями

$$
\begin{gathered}
\sigma_{s p}=3.23\left(\frac{\dot{V} / V_{0}}{\dot{\varepsilon}_{0}}\right)^{0.061} \text { при комнатной температуре, } \\
\sigma_{s p}=2.3\left(\frac{\dot{V} / V_{0}}{\dot{\varepsilon}_{0}}\right)^{0.17} \text { при } 600^{\circ} \mathrm{C}
\end{gathered}
$$

где $\dot{\varepsilon}_{0}=10^{5} \mathrm{~s}^{-1}$.

На рис. 6 показаны микрофотографии диаметрального сечения образцов, сохраненных после проведенных измерений при комнатной и повышенной температуpax с разным увеличением. Видно, что при комнатной температуре разрушение происходит путем образования и роста острых трещин, а при высокой температуре вместо трещин в материале образуются округлые поры в большом количестве. Рост круглых пор сопряжен с меньшей концентрацией напряжений. Меньшие значения откольной прочности и предела текучести привели к более завершенному отделению откольной пластины.

На рис. 7 результаты измерений откольной прочности стали 09Г2СА-А сопоставлены с подобными данными для железа Армко [17] и для реакторной стали 15Х2НМФА [4]. Более слабая зависимость откольной прочности стали 09Г2СА-А от скорости деформации привела к тому, что при относительно малых величинах $\dot{V} / V_{0}$ она близка к прочности реакторной стали, а при больших - к прочности железа. Вероятно, этот факт является следствием наличия различных спектров потенциальных очагов зарождения разрушений в этих трех материалах. 

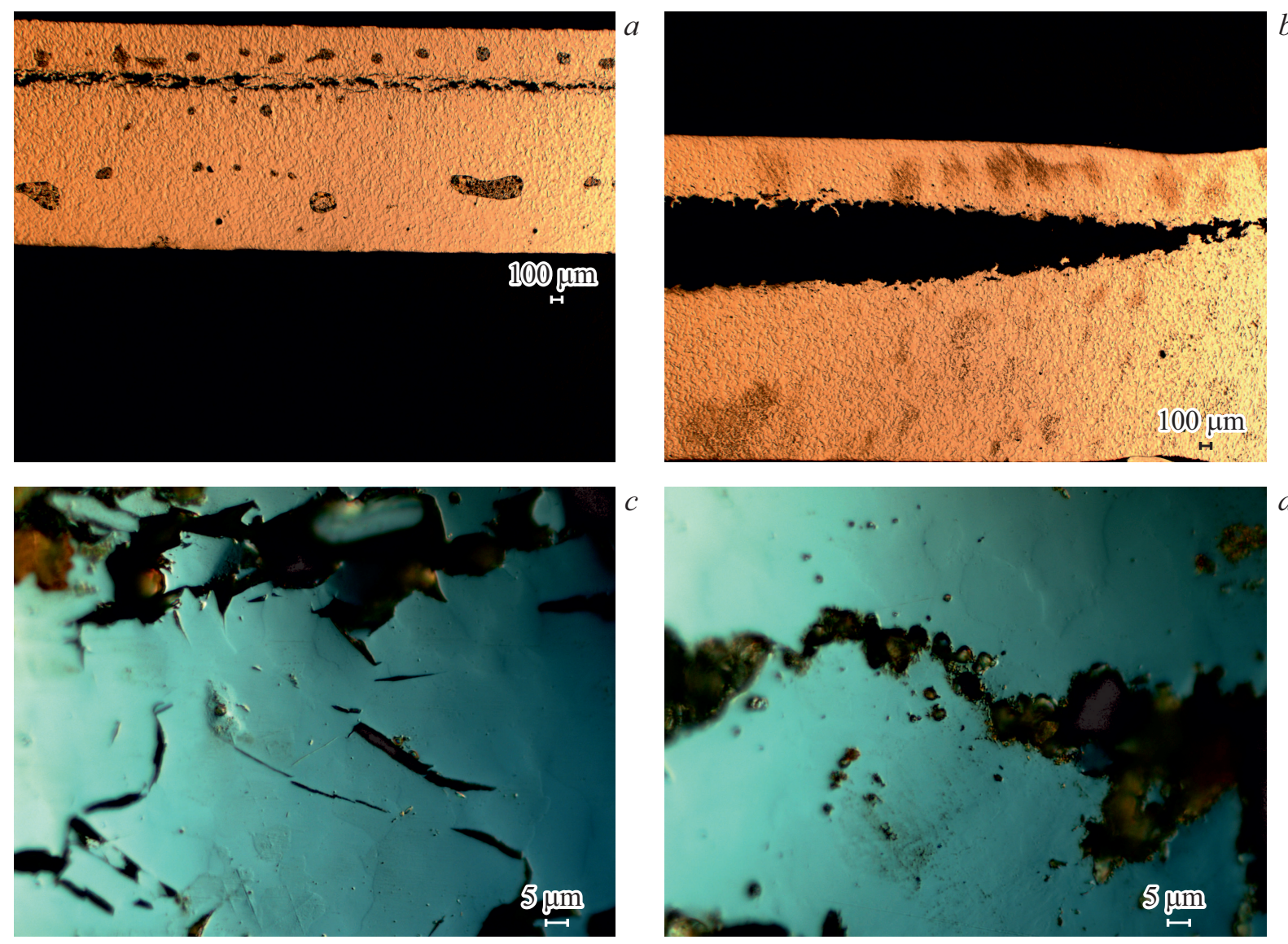

Рис. 6. Фотографии сечения откола при комнатной температуре $(a, c)$ и $599^{\circ} \mathrm{C}(b, d) ; a, b-$ увеличение $(\times 25) ; c, d-$ увеличение $(\times 1000)$.

\section{2. Затухание упругого предвестника и начальная скорость пластической деформации стали 09Г2СА-А}

На рис. 8 суммированы результаты измерений напряжений сжатия в упругом предвестнике в зависимости от пройденного волной расстояния (толщины образца) при комнатной температуре и при $600^{\circ} \mathrm{C}$. При комнатной температуре на расстояниях примерно до $1 \mathrm{~mm}$ имеет место очевидное затухание предвестника; при $600^{\circ} \mathrm{C}$ затухание регистрируется во всем исследованном диапазоне толщин образцов. Подобный переход от быстрого затухания к медленному наблюдался и для других металлов с объемно-центрированной кубической структурой и интерпретирован как следствие перехода от надбарьерного движения дислокаций, контролируемого фононной вязкостью, к термоактивационным механизмам преодоления барьеров при высоких напряжениях. Затухание упругого предвестника (волны ударного сжатия) происходит вследствие релаксации напряжений и связано со скоростью пластической деформации за его фронтом $\dot{\gamma}_{p}=\left(\dot{\varepsilon}_{x}^{p}-\dot{\varepsilon}_{y}^{p}\right) / 2$ соотношением [18]:

$$
\left.\frac{d \sigma_{x}}{d h}\right|_{\mathrm{HEL}}=-\frac{4}{3} \frac{\dot{\gamma}_{p}}{c_{l}}
$$

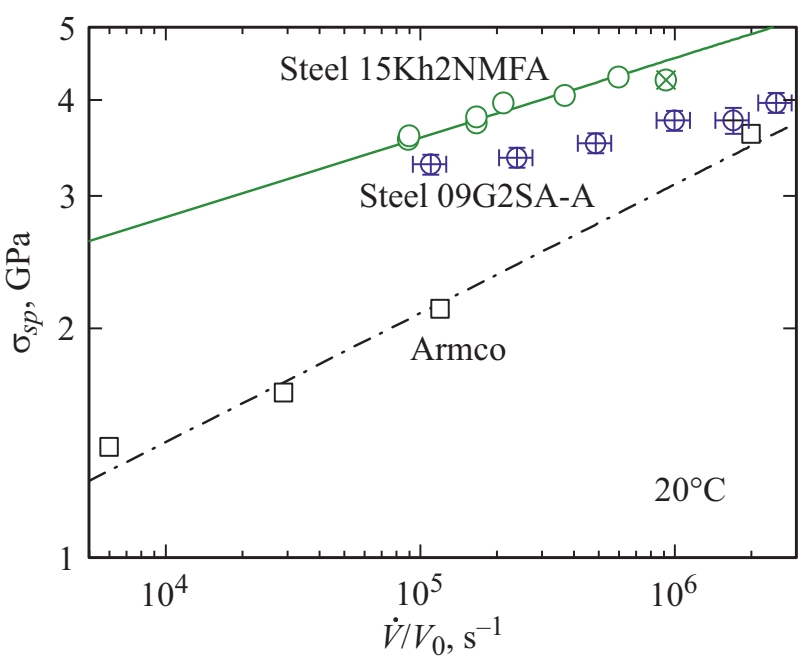

Рис. 7. Сопоставление результатов измерений откольной прочности стали 09Г2СА-А с данными для железа Армко [12] и для реакторной стали 15Х2НМФА [13].

где $h$ - пройденное волной расстояние, $G$ - модуль сдвига, $c_{l}$ - скорость распространения фронта предвестника, принятая в этом приближении равной продольной 
Таблица 2. Постановка и результаты опытов со сталью 09Г2СА-А

\begin{tabular}{|c|c|c|c|c|c|c|c|c|c|}
\hline № & $\begin{array}{l}T, \\
{ }^{\circ} \mathrm{C}\end{array}$ & $\begin{array}{c}h_{i m p} \\
\mathrm{~mm}\end{array}$ & $\begin{array}{c}u_{\text {imp }} \\
\mathrm{m} / \mathrm{s}\end{array}$ & $\begin{array}{l}h_{s m}, \\
\mathrm{~mm}\end{array}$ & $\begin{array}{l}\sigma_{H E L}, \\
\mathrm{GPa}^{*}\end{array}$ & $\begin{array}{c}\sigma_{T}, \\
\mathrm{GPa}\end{array}$ & $\begin{array}{l}\sigma_{s p} \\
\mathrm{GPa}\end{array}$ & $\begin{array}{c}\dot{V} / V_{0} \\
\mathrm{~s}^{-1}\end{array}$ & $\begin{array}{l}h_{s p} \\
\mathrm{~mm}\end{array}$ \\
\hline 1 & 20 & $\mathrm{Cu} 0.96$ & $340 \pm 10$ & 4.02 & 1.62 & 0.93 & 3.3 & $1.1 \cdot 10^{5}$ & 1.09 \\
\hline 2 & 20 & Cu 1.99 & $340 \pm 10$ & 4.02 & $\begin{array}{l}1.8 \\
1.41\end{array}$ & $\begin{array}{l}1.04 \\
0.81\end{array}$ & 2.56 & $0.8 \cdot 10^{5}$ & 2.34 \\
\hline 3 & 20 & $\mathrm{Cu} 0.47$ & $340 \pm 10$ & 2.01 & $\begin{array}{l}\text { 1.83; } \\
1.69\end{array}$ & $\begin{array}{l}1.05 \\
0.97\end{array}$ & 3.37 & $2.4 \cdot 10^{5}$ & 0.52 \\
\hline 4 & 20 & $\mathrm{Cu} 0.96$ & $340 \pm 10$ & 2.03 & $\begin{array}{l}1.8 \\
1.37\end{array}$ & $\begin{array}{l}1.04 \\
0.79\end{array}$ & 2.79 & $1.8 \cdot 10^{5}$ & 1.1 \\
\hline 5 & 20 & $\mathrm{Cu} 0.25$ & $340 \pm 10$ & 1.015 & $\begin{array}{l}2.15 \\
1.81\end{array}$ & $\begin{array}{l}1.24 \\
1.04\end{array}$ & 3.52 & $4.9 \cdot 10^{5}$ & 0.28 \\
\hline 6 & 20 & $\mathrm{Cu} 0.47$ & $340 \pm 10$ & 1.017 & $\begin{array}{l}1.83 \\
1.63\end{array}$ & $\begin{array}{l}1.05 \\
0.94\end{array}$ & 3.18 & $3.6 \cdot 10^{5}$ & 0.54 \\
\hline 7 & 20 & $\mathrm{Cu} 0.14$ & $340 \pm 10$ & 0.527 & 2.11 & 1.22 & 3.77 & $10^{6}$ & 0.16 \\
\hline 8 & 20 & $\mathrm{Cu} 0.28$ & $340 \pm 10$ & 0.488 & $\begin{array}{l}2.18 \\
1.71\end{array}$ & $\begin{array}{l}1.26 \\
0.98\end{array}$ & 3.44 & $5.3 \cdot 10^{5}$ & 0.29 \\
\hline 9 & 20 & $\mathrm{Cu} 0.044$ & $340 \pm 10$ & 0.167 & 2.83 & 1.63 & 3.98 & $2.5 \cdot 10^{6}$ & 0.058 \\
\hline 10 & 20 & $\mathrm{Cu} 0.094$ & $340 \pm 10$ & 0.183 & $\begin{array}{l}3.03 \\
2.57\end{array}$ & $\begin{array}{l}1.75 \\
1.48\end{array}$ & 3.89 & $1.6 \cdot 10^{6}$ & 0.11 \\
\hline 11 & 20 & $\mathrm{Cu} 0.046$ & $340 \pm 10$ & 0.174 & 2.43 & 1.5 & $3.77^{* *}$ & $1.7 \cdot 10^{6}$ & - \\
\hline 12 & 20 & $\mathrm{Cu} 0.2$ & $340 \pm 10$ & 0.114 & 2.96 & 1.7 & & & - \\
\hline 13 & 20 & W 1.43 & $590 \pm 20$ & 4.02 & 1.6 & 0.97 & 3.02 & $4.8 \cdot 10^{4}$ & 2.6 \\
\hline 14 & 604 & $\mathrm{Cu} 0.96$ & $340 \pm 10$ & 4.04 & $\begin{array}{l}0.88 \\
0.7\end{array}$ & $\begin{array}{l}0.49 \\
0.39\end{array}$ & 2.41 & $1.2 \cdot 10^{5}$ & 1.08 \\
\hline 15 & 599 & $\mathrm{Cu} 0.48$ & $340 \pm 10$ & 2.02 & $\begin{array}{l}1.03 \\
0.86\end{array}$ & $\begin{array}{l}0.57 \\
0.48\end{array}$ & 2.68 & $2.4 \cdot 10^{5}$ & 0.52 \\
\hline 16 & 598 & $\mathrm{Cu} 0.256$ & $340 \pm 10$ & 1.01 & $\begin{array}{l}1.39 \\
1.2\end{array}$ & $\begin{array}{l}0.77 \\
0.66\end{array}$ & 2.64 & $4.9 \cdot 10^{5}$ & 0.31 \\
\hline 17 & 604 & $\mathrm{Cu} 0.133$ & $340 \pm 10$ & 0.513 & $\begin{array}{l}1.57 \\
1.39\end{array}$ & $\begin{array}{l}0.87 \\
0.77\end{array}$ & 3.4 & $8.5 \cdot 10^{5}$ & 0.16 \\
\hline 18 & 603 & $\mathrm{Cu} 0.097$ & $340 \pm 10$ & 0.192 & 1.52 & 0.84 & 3.36 & $1.1 \cdot 10^{6}$ & 0.12 \\
\hline
\end{tabular}

Пр имечание. * верхняя строчка - напряжение на пике предвестника, нижняя — в точке минимума между упругой и пластической волнами. ** оценка снизу, откольного разрушения не было.

скорости звука. Как и для других металлических материалов [3,15], начальный участок эмпирической зависимости аппроксимируется степенной функцией

$$
\sigma_{\mathrm{HEL}}=S\left(h / h_{0}\right)^{-\alpha},
$$

где параметр $h_{0}=1 \mathrm{~mm}$. При значительном разбросе экспериментальных данных показатель $\alpha$ для всех их групп может быть взят одним и тем же, равным 0.265 , а значения коэффициента $S$ варьируются от $S_{\text {peak }}=1.96 \mathrm{GPa}$ для пиков напряжения и $S_{\min }=1.67 \mathrm{GPa}$ для точек минимума между упругой и пластической волнами при комнатной температуре до
$S_{\text {peak }}=1.3 \mathrm{GPa}$ и $S_{\min }=1.07 \mathrm{GPa}$ при $600^{\circ}$ С. Относительно малая величина показателя $\alpha$ характерна для металлов и сталей с объемно-центрированной кубической структурой.

Эмпирическая зависимость (8) трансформируется в зависимость начальной скорости пластической деформации от напряжения сдвига $\tau$ :

$$
\dot{\gamma}_{P}=\frac{3}{4}\left(\frac{\tau E^{\prime}}{S G}\right)^{\frac{\alpha+1}{\alpha}},
$$

где $E^{\prime}=\rho_{0} c_{l}^{2}-$ модуль продольной упругости, $G-$ модуль сдвига. Рассчитанные таким образом зависимо- 


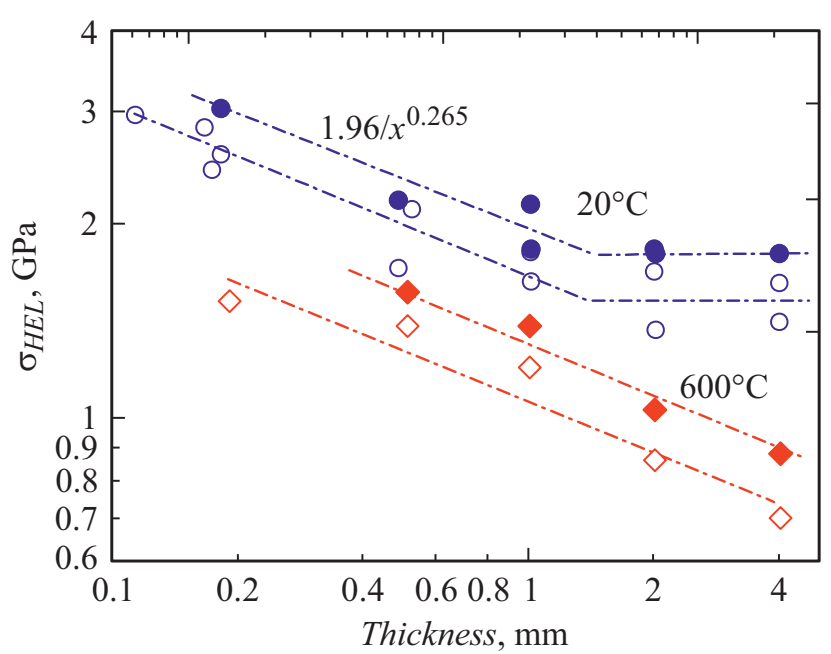

Рис. 8. Затухание упругого предвестника в стали 09Г2СА-А при комнатной температуре (кружки) и при $600^{\circ} \mathrm{C}$ (ромбы). Открытые символы соответствуют параметрам в минимуме между упругой и пластической волнами, заполненные параметрам на пике упругого предвестника.

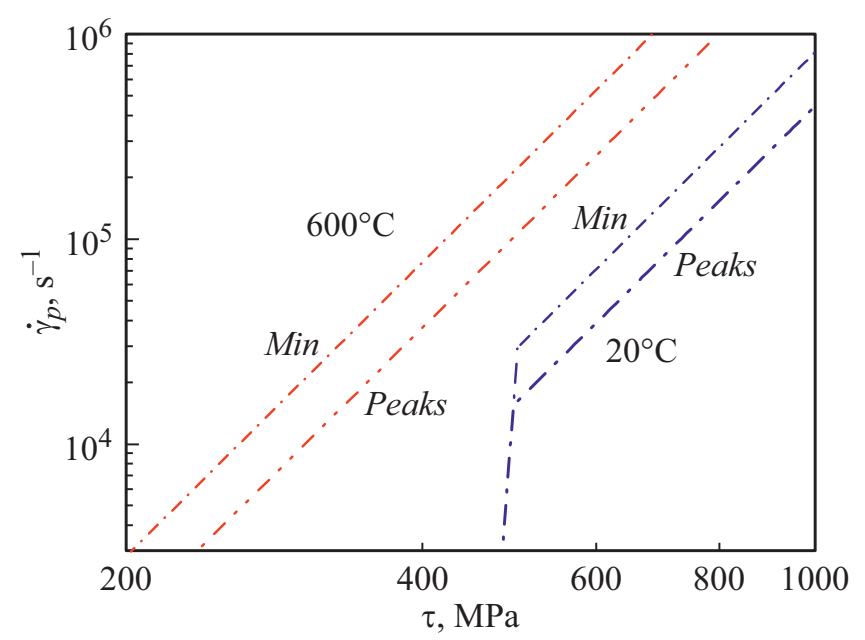

Рис. 9. Зависимости начальной скорости сдвиговой деформации от напряжения сдвига в упругом предвестнике. Расчеты выполнены для пика на фронте предвестника и для точки минимума между упругой и пластической волнами.

сти начальной скорости сдвиговой деформации от напряжения сдвига при комнатной температуре на участке быстрого затухания и при $600^{\circ} \mathrm{C}$ представлены на рис. 9 . На графике ориентировочно показан также переход к низкоскоростному режиму при комнатной температуре.

В табл. 2 представлены условия экспериментов с образцами стали 09Г2СА-А толщиной от 0.17 до $4 \mathrm{~mm}$ при различных температурах и результаты их обработки. Здесь $T$ - начальная температура образца; $h_{i m p}-$ толщина ударника (указывается также его материал); $u_{i m p}-$ скорость удара; $h_{s m}-$ толщина образца; $\sigma_{\mathrm{HEL}}-$ динамический предел упругости; $\sigma_{T}-$ динамический предел текучести; $\sigma_{s p}$ - откольная прочность;
$\dot{V} / V_{0}-$ скорость расширения при разгрузке материала из ударно-сжатого состояния.

\section{Заключение}

По результатам измерений профилей скорости свободной поверхности образцов низколегированной ферритно-перлитной стали 09Г2СА-А различной толщины определены зависимости сопротивления деформированию и разрушению материала от скорости деформирования и температуры, которые в дальнейшем могут быть использованы при построении математических моделей и определяющих соотношений. При комнатной температуре зафиксирована смена основного механизма торможения дислокаций, которая проявляется в замедлении затухания упругой волны. При $600^{\circ} \mathrm{C}$ смена механизма происходит за пределами исследованного диапазона параметров эволюции волны упругопластического ударного сжатия. Выполнена оценка напряжения пластического течения ударно-сжатой стали при $600^{\circ} \mathrm{C}$; найдено, что после высокоскоростной деформации в ударной волне напряжение пластического течения стали в 2-2.5 раза меньше начальной величины в упругом предвестнике. Определено давление начала полиморфного превращения $\alpha \rightarrow \varepsilon$ стали 09Г2СА-А при ударном сжатии, которое оказалось несколько ниже, чем в чистом железе, что объясняется присутствием марганца в составе стали. Обнаружен необычный эффект длительности исходного импульса ударного сжатия, проявляющийся при относительно небольших скоростях деформации.

\section{Финансирование работы}

Работа выполнена в рамках НИОКР „Исследование скоростных зависимостей напряжения пластического течения реакторной стали и динамической прочности бетонов, горных пород и материалов при различных скоростях деформирования“ № 17706413348200001060/226/2854-Д от 31 июля 2020 г. с использованием оборудования Московского регионального взрывного центра коллективного пользования РАН по теме Государственного задания № AАAА-А19119071190040-5.

\section{Конфликт интересов}

Авторы заявляют, что у них нет конфликта интересов.

\section{Список литературы}

[1] В.И. Горынин, М.И. Оленин. Пути повышения хладостойкости сталей и сварных соединений (ФГУП ЦНИИ КМ „Прометей“, СПб, 2017)

[2] В.А. Рыжанский, А.Г. Иванов, В.В. Жуков, В.Н. Минеев. Атомная энергетика, 79 (3), 178 (1995). 
[3] Г.В. Гаркушин, Г.И. Канель, С.В. Разоренов, А.С. Савиных. МTT, 4, 69 (2017). [G.V. Garkushin, G.I. Kanel, S.V. Razorenov, A.S. Savinykh. Mechan. Sol., $52(4), 407$ (2017). DOI: 10.3103/S0025654417040070]

[4] Г.И. Канель, Г.В. Гаркушин, А.С. Савиных, С.В. Разоренов, С.А. Атрошенко. ЖТФ, 90 (3), 441 (2020). DOI: 10.21883/JTF.2020.03.48929.295-19 [G.I. Kanel, G.V. Garkushin, A.S. Savinykh, S.V. Razorenov, S.A. Atroshenko. Tech. Phys., $65(3), 420$ (2020). DOI: $10.1134 / \mathrm{S} 1063784220030111]$

[5] E.B. Zaretsky, G.I. Kanel, S.V. Razorenov, K. Baumung. Int. J. Impact Eng., 31 (1), 41 (2005). DOI: $10.1016 /$ j.ijimpeng.2003.11.004

[6] L.M. Barker, R.E. Hollenbach. J. Appl. Phys., 45 (11), 4872 (1974). DOI: $10.1063 / 1.1663148$

[7] D.J. Dever. J. Appl. Phys., 43, 3293 (1972). DOI: $10.1063 / 1.1661710$

[8] E.B. Zaretsky. J. Appl. Phys., 106, 023510 (2009). DOI: $10.1063 / 1.3174442$

[9] L.M. Barker, R.E. Hollenbach. J. Appl. Phys., 43, 4669 (1972). DOI: $10.1063 / 1.1660986$

[10] Г.И. Канель, С.В. Разоренов, А.В. Уткин, В.Е. Фортов. Ударно-волновые явления в конденсированных средах (Янус-К, М., 1996)

[11] Г.И. Канель. Ударные волны в физике твердого тела (Физматлит, М., 2018)

[12] Г.И. Канель. ПМТФ, 42 (2), 194 (2001). [G.I. Kanel. J. Appl. Mechan. Tech. Phys. 42, 358 (2001).

DOI: 10.1023/A:1018804709273]

[13] Г.И. Канель, А.С. Савиных, Г.В. Гаркушин, С.В. Разоренов. Доклады РАН. Физика, технические науки, 496, 5 (2021). DOI: 10.31857/S2686740021010065 [G.I. Kanel, A.S. Savinykh, G.V. Garkushin, S.V. Razorenov. Dokl. Phys., 66 (2), 35 (2021) DOI: 10.1134/S1028335821020038]

[14] G.E. Duvail, R.A. Graham. Rev. Modern Phys., 49 (3), 523 (1977). DOI: 10.1103/RevModPhys.49.523

[15] T. Antoun, L. Seaman, D.R. Curran, G.I. Kanel, S.V. Razorenov, A.V. Utkin. Spall Fracture (Springer, NY., 2003)

[16] G.I. Kanel, S.V. Razorenov, A. Bogach, A.V. Utkin, D.E. Grady. Intern. J. Impact Eng., 20, 467 (1997). DOI: $10.1016 / \mathrm{S} 0734-743 \mathrm{X}(97) 87435-0$

[17] Г.И. Канель, С.В. Разоренов, Г.В. Гаркушин, С.И. Ашитков, П.С. Комаров, М.Б. Агранат. ФТТ, 56 (8), 1518 (2014). [G.I. Kanel, S.V. Razorenov, G.V. Garkushin, S.I. Ashitkov, P.S. Komarov, M.B. Agranat. Physics Solid State, 56 (8), 1569 (2014). DOI: 10.1134/S1063783414080113]

[18] G.E. Duvall. In: Strss Waves in Anelastic Solids, edited by H. Kolsky, W. Prager (Springer-Verlag, Berlin, 1964), p. 20. DOI: 10.1007/978-3-642-88288-3_2 